\title{
Memória e História do povo Xukuru do Ororubá em Pesqueira/PE no
}

\section{século XX}

SILVA, Edson. Xukuru: memórias e história dos índios da Serra de Ororubá (Pesqueira/PE), I959-I988. Recife: Editora UFPE, 2017.

\section{Arthur Victor Barros"}

Ao longo do século XIX, os intelectuais no Brasil discutiam um projeto em torno da construção de uma identidade nacional. Na História e na Literatura, o indígena foi apresentado como um símbolo da nacionalidade brasileira: uma representação associada ao ser domesticado. Essa representação do indígena perpassa uma ideia, conjugando aspectos épicos associados a uma mentalidade nativista e politicamente conservadora. A partir dessa construção, ao sujeito indígena, foi negado o direito a uma identidade própria. Mais além, as ideias em questão legitimaram a discussão sobre a miscigenação das raças, em que não existia o indígena, mas o "caboclo". As diversidades étnica, linguística e sociocultural, além da própria história, foram negadas a esses sujeitos.

$\mathrm{Na}$ contramão dessa visão positivada, a recente historiografia sobre o tema, também conhecida como "Nova História Indígena", busca evidenciar os indígenas como agentes sociopolíticos da/na História. Nesse sentido, coloca-se o livro Xukuru: memórias e história dos índios da Serra do Ororubá (Pesqueira/PE), publicado originalmente como tese de doutorado em História, na Universidade de Campinas (Unicamp), pelo historiador Edson Silva. A pesquisa faz parte dessa nova historiografia, em que é apresentada como um contraponto às narrativas oficiais. Nesse sentido, as análises atribuem a importância desses sujeitos na (re)construção de sua história. Ao mesmo tempo, as memórias Xukuru surgem como narrativas que fundamentam as reivindicações das suas memórias, afirmando sua identidade étnica e seus direitos, sobretudo, ao território.

A discussão apresentada pelo historiador tem como pilar as implicações dos discursos oficiais nas relações sociais e políticas à época; neste caso, legitimou o fenômeno das invasões dos territórios indígenas pelos senhores de engenho, no litoral, e pelos fazendeiros no interior. Essas invasões foram mais acentuadas entre os anos de I850 e I870, quando foi promulgada a Lei de Terras e declarada a extinção dos aldeamentos respectivamente. Em Pesqueira, Pernambuco, os fazendeiros invadiram os territórios Xukuru, destruindo a paisagem natural e os espaços destinados à agricultura de consumo.

\footnotetext{
"Doutorando em História pela Universidade Federal de Pernambuco (UFPE) sob a orientação da Profa. Dra. Christine Dabat. Bolsista pela Coordenação de Aperfeiçoamento de Pessoal de Nível Superior (CAPES).
} 
No lugar, foi introduzida a pecuária, produção a que os indígenas não tinham acesso. Para além das invasões, os fazendeiros forçavam acordos de venda desproporcionais ao valor da terra. Até mesmo o vício em bebida alcóolica foi utilizado para retirar as terras dos Xukuru.

É nesse contexto que está ambientada a mobilização do povo indígena Xukuru do Ororubá, habitante do antigo aldeamento de Cimbres. O território demarcado localiza-se no município de Pesqueira, distante 230 quilômetros da cidade do Recife, Pernambuco. Atualmente, o território também se estende até o município vizinho, Porção.

As relações de exploração e a disputa pelo reconhecimento oficial do direito sobre o território apresentam-se como indícios. As análises apresentadas pelo historiador fundamentam-se por meio de uma análise precisa da documentação, embora o grande momento da pesquisa, sem dúvida, sejam os relatos de memória narrados pelos indígenas, uma narrativa que possibilita construir uma discussão sobre suas reivindicações pelo direito a terra.

A construção dessa imagem remonta aos Xukuru na Guerra do Paraguai, de que participaram como voluntários ou foram recrutados compulsoriamente. O retorno do conflito garantiu, por meio da manifestação do Governo Imperial, o direito sobre as terras como recompensa aos ex-combatentes. Essa imagem, portanto, apresenta uma conexão temporal que vincula também a mobilização indígena pelo reconhecimento de sua identidade como povo, direito conquistado em 1950 com a instalação de um posto oficial do Serviço de Proteção aos Índios (SPI) na Serra do Ororubá, e o reconhecimento oficial sobre a posse das terras expresso na Constituição Federal em 1988.

No capítulo I, Edson Silva apresentou os debates da historiografia, literatura e antropologia, protagonizados por intelectuais brasileiros e estrangeiros, que tratavam sobre a construção do "caboclo" e a negação das identidades indígenas. Grande parte dessas discussões reproduzia visões preconceituosas, eurocêntricas e estereotipadas. Há, portanto, um questionamento do historiador sobre essa imagem apresentada pela narrativa oficial, construída por uma elite intelectual comprometida com os interesses sociais, políticos e econômicos de uma classe dominante conservadora e reacionária.

Nesse caso, há uma mobilização para legitimar o suposto desaparecimento dos povos indígenas, apagando sua história, uma vez que agora eles estão integrados à sociedade brasileira. A figura do "caboclo" surge, então, como fruto de uma miscigenação racial, integração cultural e dispersão no conjunto da população regional indígena. A construção desse discurso, portanto, transformou os indígenas em espectadores condenados ao 


\section{C) HISTTÓórICA}

desaparecimento "no suposto curso linear da formação da sociedade e da história do país" (SILVA, 20I7, p. 5I).

O capítulo II segue apresentando as reminiscências dos Xukuru sobre a Guerra do Paraguai. Muitos foram forçados a servir em batalhões do Exército Brasileiro no país estrangeiro. $\mathrm{O}$ capítulo trata de um tema muito pouco discutido entre os historiadores especialistas no período. As memórias sobre a guerra apresentam uma imagem das reivindicações dos Xukuru, ainda naquele momento, sobre o território da Serra do Ororubá. O fim dos aldeamentos acentuou o fenômeno da invasão do território pelos fazendeiros, que atacavam a identidade Xukuru do Ororubá afirmando que eles não eram "índios puros". Esse ponto apresentado pelo historiador evidencia as implicações do discurso oficial sobre as ações dos fazendeiros em negar as identidades, os direitos e a própria existência dos Xukuru visto que, na visão oficial, eram "caboclos".

Uma vez apresentadas essas relações, Edson Silva ressalta que foi imposta uma imagem estereotipada sobre os indígenas Xukuru Ororubá. O “índio puro" não existia. A tradição indígena, afirmada mediante rituais - independentemente da forma como o sujeito se apresenta diante da sociedade -, foi então apagada. Essas discussões são apresentadas no capítulo III por meio de uma análise detalhada da paisagem natural e as invasões do território, processo que se estende do século XVII ao XX. As análises foram possíveis graças à consulta das fontes impressas, muitas vezes desfavoráveis ao indígena, e dos próprios relatos fornecidos pelos Xukuru ao historiador.

As memórias mencionam seus antepassados, invocam os esbulhos das terras pelos fazendeiros investidores na produção pecuária e, posteriormente, na agroindústria de tomates e frutas destinadas à produção de doces e conservas na Fábrica Peixe, instalada em Pesqueira. Ao mesmo tempo, as memórias sobre a dança do Toré, símbolo de resistência sociopolítica para a reivindicação dos direitos à terra, afirmam a identidade do povo Xukuru do Ororubá.

O capítulo IV apresenta as mudanças provocadas pela introdução, na Serra do Ororubá, da pecuária, processo que modificou radicalmente a paisagem e a vida social do município de Pesqueira. Essas ações foram responsáveis por grandes deslocamentos de indígenas para a cidade, condicionando um profundo abismo social e uma extrema desigualdade social. Os Xukuru, outrora produtores de alimentos, vivenciavam a mendicância pelas ruas de Pesqueira para garantir seu sustento. Crianças e recém-nascidos conviviam com a desnutrição, muitos dos quais não resistiam e morriam. Ironicamente, essa 
situação foi agravada pela implantação das fábricas de alimentos em Pesqueira, a exemplo da Fábrica Peixe, que produzia doces e conservas.

Alguns indígenas conseguiam emprego nas fábricas, embora estivessem submetidos às péssimas condições de trabalho: prestadores de serviços ou clandestinos, a muitos eram negados os direitos trabalhistas. Já àqueles que não conseguiam trabalho na fábrica, a migração para o trabalho sazonal no corte de cana na Zona da Mata Sul em Pernambuco e na Zona da Mata Norte em Alagoas se apresentava como uma alternativa.

No capítulo V, discutem-se as mobilizações dos Xukuru no resgate de sua identidade e garantia dos direitos sobre o território na década de 1950. Aqui, as mobilizações se encontram com a figura de Cícero Cavalcanti - funcionário do SPI -, responsável por garantir aos indígenas o reconhecimento ao direito a terra, embora, na prática, como afirma a memória dos indígenas, o servidor tenha-se corrompido aos interesses dos fazendeiros. Nos relatos dos indígenas entrevistados, a imagem de Cícero é apresentada como um enganador, um ladrão que roubou objetos e documentos que comprovavam a participação dos Xukuru na Guerra do Paraguai.

Ainda no capítulo V, apresenta-se a saga épica dos índios Romão da Hora, Stendi e Félix Nascimento, que viajaram a pé até a cidade do Rio de Janeiro para solicitar a instalação de um posto oficial do SPI na Serra do Ororubá. A petição foi feita diretamente pelos indígenas ao então presidente Getúlio Vargas, por intermédio do marechal Cândido Rondon. A instalação do posto oficial garantiu aos Xukuru, ainda na década de 1950, o acesso à proteção governamental "frente à situação de permanente conflito e desmandos praticados pelos fazendeiros e pelas oligarquias políticas locais contra os grupos indígenas" (SILVA, 20I7, p. 264).

Por fim, o capítulo VI descreve as mobilizações mais recente da história do povo Xukuru; nesse caso, a aproximação dos indígenas com as Ligas Camponesas em Pernambuco durante os anos de 1950 e 1960. Essa associação ocorre em um momento em que o desenvolvimento da agroindústria é resultado da superexploração dos trabalhadores Xukuru. A implantação das Ligas na cidade de Pesqueira foi acompanhada de perto pelas autoridades políticas, policiais e até mesmo pela Igreja Católica Romana. Estes enxergavam a participação dos índios nas Ligas como fruto de uma "ingenuidade" embora as narrativas produzidas pelos Xukuru expressem uma opinião contrária, o que demonstra a existência de uma consciência ativa quanto à construção de um movimento que poderia garantir o acesso às suas terras. 


\section{C) HitșTór RICA}

A participação dos Xukuru nas Ligas Camponesas gerou uma intensa repressão antes mesmo do Golpe Militar de 1964. Com o golpe, as mobilizações dos indígenas foram duramente paralisadas embora as exigências pelos seus direitos permanecessem vivas na memória Xukuru. A redemocratização, a partir dos anos finais de I980, e, principalmente, depois da Assembleia Constituinte de 1987, permitiu uma intensa participação dos indígenas, com a decisiva atuação e liderança do Cacique Xicão nos debates sobre a nova Constituição Federal.

Os direitos adquiridos com a Carta Magna aprovada em 1988 garantiu o direito dos Xukuru sobre seu território na Serra do Ororubá embora essa garantia não representasse o acesso imediato às terras. As mobilizações pela consolidação do direito acirraram os conflitos com os fazendeiros. O processo provocou o assassinato de líderes indígenas, entre quais, o próprio Xicão, a mando dos fazendeiros, assim comprovado por demorados inquéritos da Polícia Federal. A demarcação do território indígena pelo governo federal ocorreu apenas em 200I, após muitas mobilizações indígenas e campanhas internacionais que pressionaram o governo brasileiro. Uma grande vitória do povo Xukuru do Ororubá!

Por fim, a Nova História Indígena encontra-se ameaçada. Uma série de ataques são promovidos por negacionistas inspirados nas abordagens positivistas do século XIX. Não é nenhuma novidade que esses discursos hoje sejam para, novamente, negar a identidade indígena reconhecida a duras penas por meio de políticas públicas estabelecidas no Brasil nos últimos trinta anos. Nesse contexto de negação das Ciências Humanas e Sociais, supressão de direitos e defesas de posições absurdas, a leitura do livro de Edson Silva contribui para aprendermos lições da História, evitando que erros do passado em relação aos povos indígenas e às diversas expressões socioculturais diferenciadas sejam novamente cometidos.

Recebido em: 03 de agosto de 2020.

Aprovado em: 25 de setembro de 2020. 